\title{
Prognostic significance of peritoneal washing cytology in Thai patients with gastric adenocarcinoma undergoing curative D2 gastrectomy
}

\author{
Chakrapan Euanorasetr and Panuwat Lertsithichai \\ Department of Surgery, Faculty of Medicine, Ramathibodi Hospital, Mahidol University, Bangkok 10400, Thailand
}

\begin{abstract}
Background. The aim of the present study was to determine the prognostic significance of peritoneal washing cytology (PWC) among Thai patients with gastric adenocarcinoma. Methods. Medical charts of 97 patients with gastric adenocarcinoma who underwent curative D2 gastrectomy between October 1995 and September 2005 were reviewed.

Results. A total of 22 patients $(23 \%)$ had positive PWC. Factors significantly associated with positive PWC included tumor location, macroscopic findings, histology, depth of tumor invasion, nodal involvement, TNM stage, and angiolymphatic invasion. Positive PWC was found only in tumors invading the serosa. All patients with positive PWC developed peritoneal recurrence. The sensitivity and specificity of positive $\mathrm{PWC}$ in predicting peritoneal recurrence were $61 \%$ and $100 \%$, respectively. The overall 5-year survival rates for patients with positive and negative PWC were $0 \%$ and $75 \%$, respectively.

Conclusion. Gastric adenocarcinoma with positive PWC should be considered stage IV disease. PWC should be included in the staging of gastric adenocarcinoma.
\end{abstract}

Key words Peritoneal washing cytology $\cdot$ Prognosis $\cdot$ Gastric adenocarcinoma $\cdot$ D2 gastrectomy $\cdot$ Thai patients

\section{Introduction}

Peritoneal recurrence is a common cause of death even after curative resection for gastric adenocarcinoma [16]. This is believed to be due to the presence of malignant cells that have already seeded at the time of operation but cannot be detected macroscopically. The usefulness of peritoneal washing cytology (PWC) to identify intraperitoneal free cancer cells, which have the potential for peritoneal dissemination, has been previously reported [6-16].

Offprint requests to: C. Euanorasetr

Received: July 13, 2006 / Accepted: September 30, 2006
Although PWC has been advocated by Japanese and Dutch investigators [6,10-12], it is not uniform practice in Western centers. PWC has recently been reported as an important prognostic factor in patients with gastric cancer $[1,3,17]$. The 13th Japanese edition (2nd English edition) of The Japanese Gastric Cancer Association's General Rules for Gastric Cancer, in use since 1998, defined the staging of gastric cancer by the depth of tumor, degree of nodal metastasis, liver metastasis, and PWC [18]. PWC, however, is not included in the UICC/ AJCC TNM staging system [19].

The aims of this study were to (1) determine the prevalence of positive PWC in Thai patients who underwent curative D2 gastrectomy for gastric adenocarcinoma; (2) identify clinicopathologic factors associated with positive PWC; and (3) determine the prognostic significance of PWC with regard to recurrence pattern and survival.

\section{Patients and methods}

Between October 1995 and September 2005, a series of 97 patients with gastric adenocarcinoma underwent D2 gastrectomy with curative intent at the Department of Surgery, Ramathibodi Hospital, Mahidol University, Thailand. Intraoperative PWC was performed routinely in all cases. The medical records of these patients were retrospectively reviewed. Patients were eligible for D2 gastrectomy if distant metastasis, gross peritoneal dissemination, and locally advanced disease precluding curative resection were not present. All patients underwent D2 gastrectomy by one surgeon (C.E.). Surgery was considered potentially curative (UICC-R0) or resection with curative intent when there was no gross residual tumor after surgery and the resection margins were histologically free from cancer cells.

PWC was performed as described elsewhere [20,21]. Briefly, after the abdominal cavity was opened, the 
surgeon evaluated the possibility of performing a curative resection. Physiological saline solution $(100 \mathrm{ml})$ was introduced into the abdominal cavity and manually dispersed. A sample of $20-50 \mathrm{ml}$ of fluid was subsequently recovered from several regions of the abdominal cavity, including the pouch of Douglas, the paracolic gutters, and the left subhepatic region. Cytological examination was done by experienced cytopathologists. The result of the cytological examination was reported 1 week after surgery because a quick and accurate assessment of the peritoneal fluid was not available in our institution. The D2 gastrectomy was carried out without knowledge of the cytological status. Standard D2 gastrectomy, according to the Japanese Research Society for Gastric Cancer, was performed. The disease was staged according to the UICC/AJCC TNM staging system. Recurrence was categorized as peritoneal, locoregional, or distant. Peritoneal recurrence was documented by positive cytology in the ascites fluid or by peritoneal nodules on radiological imaging. Recurrence involving the ovaries (Krukenberg's tumor) was considered a peritoneal recurrence.

Clinicopathological characteristics of patients with positive PWC were compared with those of patients with negative PWC. Student's $t$-test and the chi-squared test were used to test statistical hypotheses. Multiple logistic regression was used to identify significant and independent characteristics associated with positive PWC. Survival probabilities were estimated with the Kaplan-Meier method, and the $95 \%$ confidence intervals $(\mathrm{CI})$ were estimated using Greenwood's method. The log-rank test was used to test for differences between two survival curves. Multivariable Cox regression was used to obtain a set of independent prognostic factors significantly associated with overall survival. Statistical significance was defined as $P \leq 0.05$. All statistical analyses were performed using STATA version 7 (Stata, College Station, TX, USA).

\section{Results}

PWC was positive for cancer cells in 22 of 97 patients $(23 \%)$ and was negative in 75 of 97 patients $(77 \%)$. The median age of patients with positive PWC was 58.5 years (range $41-76$ years), and 60 years (range 31-83 years) for those with negative PWC. The median follow-up period was 49 months (range 3-119 months).

\section{Clinicopathological characteristics}

The relation between the PWC result and various clinicopathological characteristics is presented in Table 1. There were significant associations between positive PWC and more proximal tumor location, scirrhous tumor, poorly differentiated histology, presence of angiolymphatic invasion, pT3 or pT4 tumor, regional lymph node involvement, and higher TNM staging. There was no association between positive PWC and sex or between positive PWC and age.

Multiple logistic regression revealed only higher TNM staging and presence of angiolymphatic invasion to be independently associated with positive PWC (Table 2). There was no significant interaction between these two characteristics.

\section{Peritoneal recurrence}

At the end of this study, 54 patients (56\%) remained free of disease, and 43 patients (44\%) had recurrent disease. Among all of the patients, 28 (29\%) had died from recurrent disease and 15 patients (15\%) were still alive with recurrence. All 22 patients with positive cytology developed peritoneal recurrence. Locoregionl and distant recurrence was also seen in 10 of 22 patients $(46 \%)$ and 5 of 22 patients (23\%), respectively. The relation between peritoneal recurrence and PWC results is presented in Table 3. Whereas all positive PWC patients developed peritoneal recurrence $(100 \%)$, negative PWC patients developed peritoneal recurrence in only 14 of 75 patients (19\%). Patients with positive PWC had a 5.4 times higher risk of peritoneal recurrence (95\% CI 3.3-8.6). The sensitivity and specificity of positive cytology in predicting peritoneal recurrence in our study were $61 \%$ and $100 \%$, respectively. The positive predictive value and the negative predictive value were $100 \%$ and $81 \%$, respectively.

\section{Survival}

At the last follow-up, 6 of 22 patients (27\%) with positive PWC were still alive with recurrence and 16 of 22 patients $(73 \%)$ died from recurrent disease. Most deaths occurred within 2 years after surgery. The median survival time for patients with positive PWC was 19 months (range 4-31 months), and for patients with negative PWC this was 29 months (range 4-119 months). The overall 5-year survival rates for patients with positive PWC and negative PWC were $0 \%$ and $75 \%$ (95\% CI 60\%-85\%), respectively. The 5-year disease-free survival rates for patients with positive PWC and negative PWC were $0 \%$ and $63 \%$ (95\% CI $48 \%-$ $74 \%$ ), respectively.

Kaplan-Meier estimates of the survival curves for patients with positive PWC and for those with negative PWC are presented in Fig. 1. There is a clear survival difference between the two groups of patients, with the $\log$-rank test $P<0.001$. The prognosis for patients with positive PWC is similar to that of patients with TNM stage IV disease, as can be seen when Fig. 1 is compared 
Table 1. Clinicopathological characteristics

\begin{tabular}{|c|c|c|c|}
\hline Characteristics & $\begin{array}{l}\text { Negative cytology } \\
\quad(n=75)\end{array}$ & $\begin{array}{l}\text { Positive cytology } \\
\quad(n=22)\end{array}$ & $P^{*}$ \\
\hline \multicolumn{4}{|l|}{ Sex } \\
\hline Male & $40(53 \%)$ & $11(50 \%)$ & \multirow[t]{2}{*}{0.783} \\
\hline Female & $35(47 \%)$ & $11(50 \%)$ & \\
\hline \multicolumn{4}{|l|}{ Tumor location } \\
\hline Upper + middle & $37(49 \%)$ & $18(82 \%)$ & \multirow[t]{2}{*}{0.007} \\
\hline Lower & $38(51 \%)$ & $4(18 \%)$ & \\
\hline \multicolumn{4}{|l|}{ Macroscopic findings } \\
\hline Scirrhous & $6(8 \%)$ & $8(82 \%)$ & \multirow[t]{2}{*}{0.001} \\
\hline Nonscirrhous & $69(92 \%)$ & $14(64 \%)$ & \\
\hline \multicolumn{4}{|l|}{ Histology } \\
\hline Differentiated & $25(33 \%)$ & $2(9 \%)$ & \multirow[t]{2}{*}{0.026} \\
\hline Poorly differentiated & $50(67 \%)$ & $20(91 \%)$ & \\
\hline \multicolumn{4}{|l|}{ Angiolymphatic invasion } \\
\hline Yes & $24(32 \%)$ & $18(82 \%)$ & \multirow[t]{2}{*}{$<0.001$} \\
\hline No & $51(68 \%)$ & $4(18 \%)$ & \\
\hline \multicolumn{4}{|l|}{ Tumor depth } \\
\hline pT1-2 & $14(19 \%)$ & 0 & \multirow[t]{2}{*}{0.028} \\
\hline pT3-4 & $61(81 \%)$ & $22(100 \%)$ & \\
\hline \multicolumn{4}{|l|}{ Nodal involvement } \\
\hline No & $14(19 \%)$ & 0 & \multirow[t]{2}{*}{0.028} \\
\hline Yes & $61(81 \%)$ & $22(100 \%)$ & \\
\hline \multicolumn{4}{|l|}{ TNM stage } \\
\hline IA & $2(3 \%)$ & 0 & \multirow[t]{6}{*}{0.01} \\
\hline IB & $7(9 \%)$ & 0 & \\
\hline II & $11(15 \%)$ & $1(5 \%)$ & \\
\hline IIIA & $26(35 \%)$ & $1(5 \%)$ & \\
\hline IIIB & $9(12 \%)$ & $4(18 \%)$ & \\
\hline IV & $20(27 \%)$ & $16(73 \%)$ & \\
\hline
\end{tabular}

* According to the chi-squared test

Table 2. Significant independent predictors of positive peritoneal washing cytology; multiple logistic regression

\begin{tabular}{lccc}
\hline Variable & Odds ratio & $95 \%$ CI & $P$ \\
\hline TNM staging & $2.21^{\mathrm{a}}$ & $1.16-4.23$ & 0.016 \\
Presence of angiolymphatic invasion & 3.90 & $1.04-14.66$ & 0.044 \\
\hline
\end{tabular}

${ }^{a}$ Odds ratio per one higher TMN stage; e.g., the odds of stage IV is 2.21 times that of stage III

Table 3. Relation between peritoneal recurrence and peritoneal washing cytology results

\begin{tabular}{lcc}
\hline $\begin{array}{l}\text { Total } \\
(n=97)\end{array}$ & $\begin{array}{c}\text { Positive cytology } \\
(n=22)\end{array}$ & $\begin{array}{c}\text { Negative cytology } \\
(n=75)\end{array}$ \\
\hline Peritoneal recurrence $(n=36)$ & 22 & 14 \\
No peritoneal recurrence $(n=61)$ & 0 & 61 \\
\hline
\end{tabular}

with Fig. 2. Among the potential prognostic variables for both overall and disease-free survival (Table 1), only three were significant on multivariable Cox regression: the TNM stage grouping, angiolymphatic invasion, and positive PWC (Table 4).

\section{Discussion}

Peritoneal washing cytology for detecting intraperitoneal free cancer cells was first established by Moore et al. in 1961 [22]. For gastric carcinoma, Nakajima et al. in 
Table 4. Significant independent predictors of poor survival after D2 gastrectomy for gastric cancer; multivariable Cox regression

\begin{tabular}{lccc}
\hline Variable & Hazard ratio & $95 \%$ CI & $P$ \\
\hline TNM staging & $2.50^{\mathrm{a}}$ & $1.31-4.79$ & 0.006 \\
Presence of angiolymphatic invasion & 5.75 & $1.68-19.68$ & 0.005 \\
Positive peritoneal washing cytology & 3.80 & $1.54-9.35$ & 0.004 \\
\hline
\end{tabular}

${ }^{a}$ Hazard ratio per one higher TMN stage; e.g., the hazard of stage IV is 2.5 times that of stage III

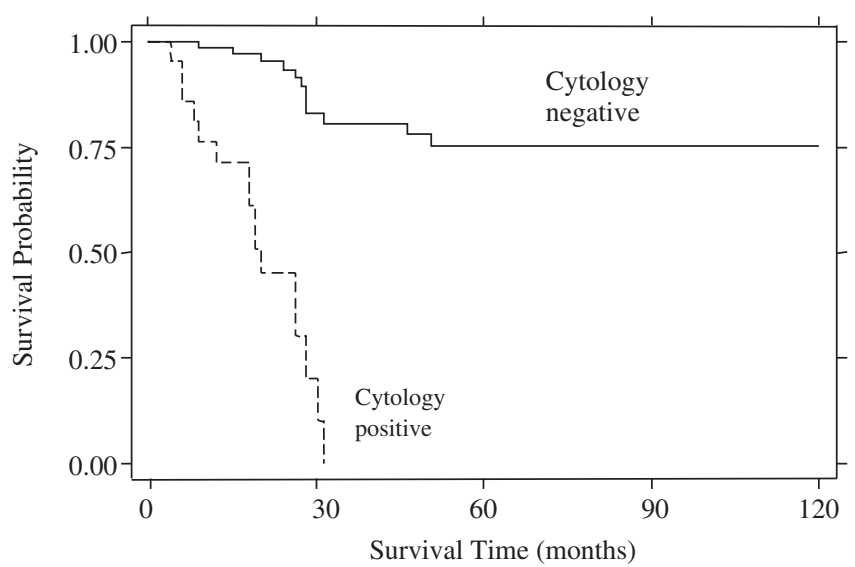

Fig. 1. Kaplan-Meier estimates of the survival probabilities associated with positive peritoneal washing cytology ("cytology positive") and negative cytology ("cytology negative") after D2 gastrectomy

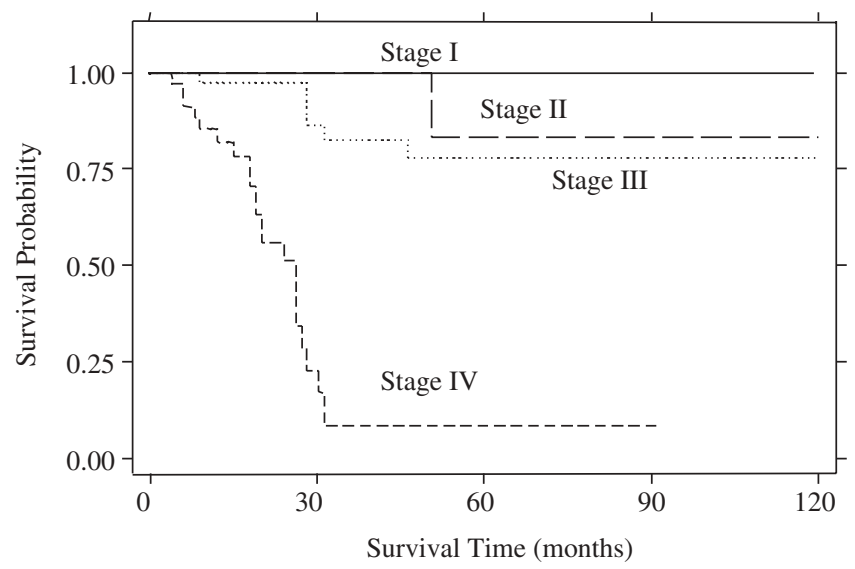

Fig. 2. Kaplan-Meier estimates of the survival probabilities associated with various stages of gastric cancer (stages I-IV according to the TNM classification) after D2 gastrectomy

1978 reported that PWC was a good predictor of prognosis [12], and similar results were obtained by other investigators [2,7-14,23]. In the present study, the prevalence of positive PWC in the peritoneal washing fluid was $23 \%$ (22/97). The overall prevalence of positive $\mathrm{PWC}$ reported in the literature ranges from $4.4 \%$ to $55.0 \%[1-3,6-8,10,20,21]$. This wide variation reflects differences in patient selection and treatment. Some investigators included patients with macroscopic peritoneal dissemination or ascites (or both), whereas other included only those with early gastric cancer [1-3,6$10,20,21]$.

In the present study, seven pathological variables (including tumor location, macroscopic findings, histology, angiolymphatic invasion, depth of tumor invasion, nodal involvement, and TNM stage grouping) were significantly associated with positive PWC (Table 1), although on multiple logistic regression only TNM stage grouping and angiolymphatic invasion remained significant (Table 2). PWC was not positive when tumor invasion was limited to the bowel wall (pT1 and pT2). However, when the tumor invaded the serosa (pT3) and adjacent organs (pT4), the percentages of positive PWC were $19 \%$ and $73 \%$, respectively. Previous studies also reported that serosal invasion was associated with a higher likelihood of cytological positivity [2,3,13,21,24]. It seems that the invasion of gastric serosa is a prerequisite for transperitoneal metastasis.

All gastric cancer patients who had positive PWC in this study had regional lymph node involvement or advanced disease (stage II or more). Similarly, other reports found nodal involvement to be associated with a high incidence of positive cytology $[2,10,25]$, and a statistically significant association was found between positive cytology and advanced stage cancer [1$3,7,10,25,26]$. Although some previous reports confirmed the association found in this study between poor tumor differentiation and positive PWC [3,7], others found no such association [17,24]. The present study also revealed that tumors with angiolymphatic invasion had a significantly higher rate of positive PWC. This result supports the theory of peritoneal carcinomatosis, which suggests shedding of cancer cells from both the serosal surface and the lymphatic system [13].

All patients with positive PWC in this study developed peritoneal recurrence. The specificity and positive predictive value of $\mathrm{PWC}$ in predicting peritoneal recurrence was high $(100 \%)$, but the sensitivity was only $61 \%$. The sensitivity of PWC was also relatively low in previous reports, ranging from $14 \%$ to $70 \%$ $[1,3,5,14,26]$. The relatively high false-negative rate might imply technical flaws such as incomplete sampling 
in the lavage process. False-positive PWC has also been recognized, with a rate of $4.5 \%-5.0 \%$, probably due to the presence of reactive mesothelial cells $[20,21,26]$. To reduce the false-negative rate, several authors have introduced more sensitive methods for detecting peritoneal dissemination, including immunohistochemistry and molecular biology techniques such as reverse transcriptase-polymerase chain reaction (RT-PCR) for expressing carcinoembryonic antigen (CEA) mRNA [20,24,27-30] or trypsinogen mRNA [31] in the peritoneal washing fluid. However, these techniques are timeconsuming, expensive, and laborious compared with conventional cytology.

In this study, positive PWC was associated with a poor prognosis, even following curative surgery, with no patient surviving more than 5 years. Multivariable Cox regression found PWC to be one of the most significant independent predictors of survival. Positive PWC as an independent predictor of survival has been previously reported by many investigators $[2,3,6,8-$ $14,24]$ with a mean survival time of 8.6-18.4 months $[1,7,8,17,20,24,32]$. However, the influence of positive PWC on the survival of patients with gastric cancer has not been consistent. Abe et al. in 1995 [33] reported that PWC was not an independent predictor of survival. Bonenkamp et al. in 1996 found positive PWC to be a significant predictor of poor survival [8] but not an independent predictor when $\mathrm{pT}$ and $\mathrm{pN}$ stage was taken into account.

PWC should be included as an integral part of gastric cancer staging and classification. Patients with positive PWC have essentially stage IV disease (compare Figs. 1 and 2) even in the absence of macroscopic peritoneal dissemination. PWC may also serve as a guide in the decision to employ controversial adjuvant treatments such as intraperitoneal chemohyperthermia [34-36] or carbon-absorbed mitomycin C [37].

\section{Conclusion}

A total of $23 \%$ of patients undergoing D2 gastrectomy with curative intent for gastric adenocarcinoma had positive PWC. There were significant associations between positive PWC and several clinicopathological factors, including tumor location, macroscopic findings, histology, depth of tumor invasion, nodal involvement, TNM stage grouping, and angiolymphatic invasion, the latter two being the only independent characteristics on multivariable analysis. Positive PWC was confined to patients with gastric cancer invading the serosa (pT3 and pT4). Positive PWC was a significant predictor of peritoneal recurrence, with a sensitivity of $61 \%$, specificity of $100 \%$, positive predictive value of $100 \%$, and negative predictive value of $81 \%$. Patients with positive
PWC had a poor prognosis with no 5-year survival. These patients should be considered to have stage IV disease and are unlikely to benefit from D2 gastrectomy. It seems prudent to add PWC as an important component in the staging of gastric adenocarcinoma.

Acknowledgments The principal author (CE) would like to acknowledge the invaluable experience he received at the National Cancer Center Hospital in Tokyo, Japan, in 1995, as well as the great kindness shown to him by Professor Keiichi Maruyama and his colleagues.

\section{References}

1. Cetin B, Atalay C, Aslan S, Babacan B, Hatipoglu C, Akinci M, et al. Peritoneal carcinoembryonic antigen level for predicting locoregional and distant spread of gastric cancer. Surg Today 2005;35:919-24.

2. Boku T, Nakane Y, Minoura T, Takada H, Yamamura M, Hioki $\mathrm{K}$, et al. Prognostic significance of serosal invasion and free intraperitoneal cancer cells in gastric cancer. Br J Surg 1990;77:436-9.

3. Bando E, Yonemura Y, Takeshita Y, Taniguchi K, Yasul T, Yoshimitsu Y, et al. Intraoperative lavage for cytological examination in 1,297 patients with gastric carcinoma. Am J Surg 1999; $178: 256-62$.

4. Moriguchi S, Maehara Y, Korenaga D, Sugimachi K, Nose Y. Risk factors which predict pattern of recurrence after curative surgery for patients with advanced gastric cancer. Surg Oncol 1992;1:341-6.

5. Li JK, Zheng M, Miao CW, Zhang JH, Ding GH, Wu WS. Peritoneal lavage cytology and carcinoembryonic antigen determination in predicting peritoneal metastases and prognosis of gastric cancer. World J Gentroenterol 2005;11:7374-7.

6. Kodera Y, Nakanishi H, Ito S, Mochizuki Y, Ohashi N, Yamamura $Y$, et al. Prognostic significance of intraperitoneal cancer cells in gastric carcinoma: analysis of real time reverse transcriptase polymerase chain reaction after 5 years of follow-up. J Am Coll Surg 2006;2002:231-6.

7. Suzuki T, Ochiai T, Hayashi H, Nakajima K, Yasumoto A, Hishikawa E, et al. Importance of positive peritoneal lavage cytology findings in the stage grouping of gastric cancer. Surg Today 1999;29:111-5.

8. Bonenkamp JJ, Songun I, Hermans J, van de Velde CJ. Prognostic value of positive cytology findings from abdominal washings in patients with gastric cancer. Br J Surg 1996;83:672-4.

9. Kodera Y, Yamamura Y, Shimizu Y, Torii A, Hirai T, Yasui K, et al. Peritoneal washing cytology: prognostic value of positive finding in patients with gastric carcinoma undergoing a potentially curative resection. J Surg Oncol 1999;72:60-4.

10. Hayes N, Wayman J, Wadehra V, Scott DJ, Raimes SA, Griffin SM. Peritoneal cytology in the surgical evaluation of gastric carcinoma. Br J Cancer 1999;79:520-4.

11. Sugita Y, Fujiwara Y, Taniguchi H, Mori T, Ishii T, Niwa H, et al. Quantitative molecular diagnosis of peritoneal lavage fluid for prediction of peritoneal recurrence in gastric cancer. Int J Oncol 2003;23:1419-23.

12. Nakajima T, Harashima S, Hirata M, Kajitani T. Prognostic and therapeutic values of peritoneal cytology in gastric cancer. Acta Cytol 1978;22:225-9.

13. Chuwa EWL, Khin LW, Chan WH, Ong HS, Wong WK. Prognostic significance of peritoneal lavage cytology in gastric cancer in Singapore. Gastric Cancer 2005;8:228-37.

14. Wu CC, Chen JT, Chang MC, Ho WL, Chen CY, Yeh DC, et al. Optimal surgical strategy for potentially curable serosa-involved 
gastric carcinoma with intraperitoneal free cancer cells. J Am Coll Surg 1997;184:611-7.

15. Miyashiro I, Takachi K, Doki Y, Ishikawa O, Ohigashi $\mathrm{H}$, Murata K, et al. When is curative gastrectomy justified for gastric cancer with positive peritoneal lavage cytology but negative macroscopic peritoneal implant? World J Surg 2005:29:1131-4.

16. Burke EC, Karpeh MS Jr, Conlon KC, Brennan MF. Peritoneal lavage cytology in gastric cancer: an independent predictor of outcome. Ann Surg Oncol 1998;5:411-5.

17. Iitsuka Y, Shiota S, Matsui T, Murata Y, Kimura A, Koga S. Relationship between the cytological characteristics of intraperitoneal free cancer cells and the prognosis in patients with gastric cancer. Acta Cytol 1990;34:437-42.

18. Japanese Gastric Cancer Association. Japanese Classification of Gastric Carcinoma, 2nd English edition. Gastric Cancer 1998;1: $10-24$.

19. Greene FL, Page DL, Fleming ID, Fritz, A, Balch CM, Morrow M, editors. AJCC Cancer Staging Manual, 6th edition. New York: Springer-Verlag; 2002.

20. Ribeiro U, Safatle-Ribeiro AV, Zilberstein B, Murerino D, Yagi $\mathrm{OK}$, Bresciani CC, et al. Dose the intraoperation peritoneal lavage cytology add prognostic information in patients with potentially curative gastric resection? J Gastrointest Surg 2006;10: 170-7.

21. Iitsuka Y, Kaneshima S, Tanida O, Takeuchi T, Koga S. Intraperitoneal free cancer cells and their viability in gastric cancer. Cancer 1979;44:1479-80.

22. Moore GE, Sako K, Kondo T, Badillo J, Burke E. Assessment of the exfoliation of tumor cells into the body cavities. Surg Gynecol Obstet 1961;112:469-74.

23. Vogel P, Ruschoff J, Kummel S, Zirngibl H, Hofstadter F, Hohenberger W, et al. Prognostic value of microscopic peritoneal dissemination: comparison between colon and gastric cancer. Dis Colon Rectum 2000;43:92-100.

24. Bentrem D, Wilton A, Mazumdar M, Brennan M, Coit D. The value of peritoneal cytology as a preoperative predictor in patients with gastric carcinoma undergoing a curative resection. Ann Surg Oncol 2005;12:347-53.

25. Schott A, Vogel I, Krueger U, Kalthoff H, Schreiber HW, Schmiegel W, et al. Isolated tumor cells are frequently detectable in the peritoneal cavity of gastric and colorectal cancer patients and serve as a new prognostic marker. Ann Surg 1998;227:372-9.

26. Suzuki T, Ochiai T, Hayashi H, Hori S, Shimada H, Isono K. Peritoneal lavage cytology findings as prognostic factor for gastric cancer. Semin Surg Oncol 1999;17:103-7.
27. Asao T, Fukuda T, Yazawa S, Nagamachi Y. Carcinoembryonic antigen levels in peritoneal washings can predict peritoneal recurrence after curative resection of gastric cancer. Cancer 1991;68: 44-7.

28. Nishiyama M, Takashima I, Tanaka T, Yoshida K, Toge T, Nagata $\mathrm{H}$, et al. Carcinoembryonic antigen levels in the peritoneal cavity: useful guide to peritoneal recurrence and prognosis for gastric cancer. World J Surg 1995;19:133-7.

29. Bold RJ, Ota DM, Ajani JA, Mansfield PF. Peritoneal and serum tumour markers predict recurrence and survival of patients with resectable gastric cancer. Gastric Cancer 1999;2:1-7.

30. Kodera Y, Nakanishi H, Yamamura Y, Shimizu Y, Torii A, Hirai $\mathrm{T}$, et al. Prognostic value and clinical implications of disseminated cancer cells in the peritoneal cavity detected by reverse transcriptase-polymerase chain reaction and cytology. Int J Cancer 1998;79:429-33.

31. Fujimura T, Ohta T, Kitagawa H, Fushida S, Nishimura GI, Yonemura Y, et al. Trypsinogen expression and early detection for peritoneal dissemination in gastric cancer. J Surg Oncol 1998; 69:71-5.

32. Elaraj DM, Ettinghausen SE. Cytological analysis of peritoneal washings: now part of the standard preoperative staging evaluation for patients with resectable gastric cancer? Ann Surg Oncol 2005;12:1-3.

33. Abe S, Yoshimura H, Tabara H, Tachibana M, Monden N, Nakamura T. et al. Curative resection of gastric cancer: limitation of peritoneal lavage cytology in predicting the outcome. J Surg Oncol 1995;59:226-9.

34. Kim JY, Bae HS. A controlled clinical study of serosa - invasive gastric carcinoma patients who underwent surgery plus intra peritoneal hyperthermo-chemo-perfusion (IHCP). Gastric Cancer 2001;4:24-33.

35. Yonemura Y, de Aretxabala X, Fujimura T, Fushida S, Katayama $\mathrm{K}$, Bandou E, et al. Intraoperative chemohyperthermic peritoneal perfusion as an adjuvant to gastric cancer: final results of a randomized controlled study. Hepatogastroenterology 2001;48:177682.

36. Yonemura Y, Ninomiya I, Kaji M, Sugiyama K, Fujimura K, Sawa $\mathrm{T}$, et al. Prophylaxis with intraoperative chemohyperthermia against peritoneal recurrence of serosal invasion-positive gastric cancer. World J Surg 1995;19:450-5.

37. Hagiwara A, Takahashi T, Kojima O, Sawai K, Hamaguchi T, Yamane T, et al. Prophylaxis with carbon-absorbed mitomycin against peritoneal recurrences or gastric cancer. Lancet 1992;339: 629-31. 